Article

\title{
Survival-Associated Metabolic Genes in Human Papillomavirus-Positive Head and Neck Cancers
}

\author{
Martin A. Prusinkiewicz ${ }^{1,+}+\mathbb{D}$, Steven F. Gameiro ${ }^{1,+}$, Farhad Ghasemi ${ }^{2}$, Mackenzie J. Dodge ${ }^{1}$, \\ Peter Y. F. Zeng ${ }^{3}$, Hanna Maekebay ${ }^{1}$, John W. Barrett ${ }^{3}$, Anthony C. Nichols ${ }^{3,4,5}$ (D) \\ and Joe S. Mymryk 1,3,4,5,*(D) \\ 1 Department of Microbiology and Immunology, The University of Western Ontario, \\ London, ON N6A 3K7, Canada; mprusink@uwo.ca (M.A.P.); sgameiro@uwo.ca (S.F.G.); \\ mdodge@uwo.ca (M.J.D.); hmaekeba@uwo.ca (H.M.) \\ 2 Department of Surgery, The University of Western Ontario, London, ON N6A 3K7, Canada; \\ fghasemi2019@meds.uwo.ca \\ 3 Department of Otolaryngology, Head \& Neck Surgery, The University of Western Ontario, \\ London, ON N6A 3K7, Canada; yzeng2023@meds.uwo.ca (P.Y.F.Z.); john.barrett@lhsc.on.ca (J.W.B.); \\ anthony.nichols@lhsc.on.ca (A.C.N.) \\ 4 Department of Oncology, The University of Western Ontario, London, ON N6A 3K7, Canada \\ 5 London Regional Cancer Program, Lawson Health Research Institute, London, ON N6C 2R5, Canada \\ * Correspondence: jmymryk@uwo.ca; Tel.: +1-519-685-8600 (ext. 53012) \\ + Contributed equally to this project.
}

Received: 29 November 2019; Accepted: 16 January 2020; Published: 20 January 2020

check for updates

\begin{abstract}
Human papillomavirus (HPV) causes an increasing number of head and neck squamous cell carcinomas (HNSCCs). Altered metabolism contributes to patient prognosis, but the impact of HPV status on HNSCC metabolism remains relatively uncharacterized. We hypothesize that metabolism-related gene expression differences unique to HPV-positive HNSCC influences patient survival. The Cancer Genome Atlas RNA-seq data from primary HNSCC patient samples were categorized as $73 \mathrm{HPV}$-positive, $442 \mathrm{HPV}$-negative, and 43 normal-adjacent control tissues. We analyzed 229 metabolic genes and identified numerous differentially expressed genes between HPV-positive and negative HNSCC patients. HPV-positive carcinomas exhibited lower expression levels of genes involved in glycolysis and higher levels of genes involved in the tricarboxylic acid cycle, oxidative phosphorylation, and $\beta$-oxidation than the HPV-negative carcinomas. Importantly, reduced expression of the metabolism-related genes SDHC, COX7A1, COX16, COX17, ELOVL6, GOT2, and SLC16A2 were correlated with improved patient survival only in the HPV-positive group. This work suggests that specific transcriptional alterations in metabolic genes may serve as predictive biomarkers of patient outcome and identifies potential targets for novel therapeutic intervention in HPV-positive head and neck cancers.
\end{abstract}

Keywords: human papillomavirus; head and neck cancer; cancer metabolism; glycolysis; cellular respiration; TCGA

\section{Introduction}

As of 2018, head and neck squamous cell carcinomas (HNSCC), namely cancers of the oral cavity, oropharynx, nasopharynx, larynx, and hypopharynx, had the 8th highest combined incidence rate and the 5th highest 5-year prevalence as interpreted from GLOBOCAN data [1,2]. This translates to 834,860 new head and neck cancers per year and 2,164,271 active head and neck cancers within the past five years worldwide [1,2]. Recent incidence rates of some oropharyngeal cancers, such as those of the tonsils and base of the tongue, have been rapidly increasing due to high-risk human papillomavirus 
(HPV) infection [3]. Infection by specific high-risk HPVs, such as HPV16, was only recognized as a contributing factor for oropharyngeal cancer by the International Agency for Research on Cancer in 2003 [4]. However, the number of oropharyngeal cancers caused by HPV has risen at epidemic rates over the last decades in many parts of the world [5], while the number of HNSCCs caused by exposure to mutagens from excessive smoking and drinking has been decreasing [6].

HPV-positive (HPV+) HNSCCs are distinct from their HPV-negative (HPV-) counterparts from a molecular perspective, with characteristic genetic, epigenetic, and protein expression profiles [7-9]. In addition, patient outcomes are generally far more favorable for HPV+ than HPV- HNSCC [10]. The underlying molecular reasons for this difference are not entirely clear. However, approximately $10 \%$ of all HPV+ HNSCC patients still succumb to their disease [11]. Identification of prognostic markers predicting favorable survival outcomes in patients could allow for treatment deintensification, thereby avoiding potential lifelong complications from unnecessarily aggressive treatments. Alternatively, identification of cellular pathways contributing to poor prognosis could lead to the development of new effective therapies for those not responding to the current standard of care.

Altered metabolism is a cancer hallmark that was recognized decades ago with the discovery of the Warburg effect, also known as aerobic glycolysis [12]. Aerobic glycolysis involves an upregulation of glycolysis despite the presence of ample oxygen for efficient cellular respiration. Many tumours exhibit this metabolic phenotype, as it provides rapid energy and an ample supply of precursors for macromolecule biosynthesis. Tumours can also rely on cellular respiration, often via glutaminolysis, which is the breakdown of glutamine into intermediates of the tricarboxylic acid (TCA) cycle. [13]. TCA intermediates can be funneled off for macromolecule biosynthesis. Many viruses are known to extensively modulate cellular metabolic processes to facilitate infection [14]. These changes can include similar tumour-associated metabolic changes as described above. Infection with HPV has been shown to phenocopy cancer-like metabolic changes that are maintained in HPV+ HNSCC [15]. Examination of how the metabolic phenotype differs between HPV+ and HPV- HNSCC could lead to the identification of targetable metabolic changes and potential new treatment options that are specific for either HPV+ HNSCCs or HPV- HNSCCs. Admittedly, cancer metabolism is complex as it impinges on a variety of other cellular processes and can vary across an individual tumour [16]. In addition, tumours can be highly adaptive to metabolic perturbations [16]. Identifying multiple metabolic targets that are specific to a cancer type from a large dataset that contains information from an extensive number of tumours, such as The Cancer Genome Atlas (TCGA), is an ideal step towards selecting or generating useful anti-metabolic cancer therapeutics.

In this study, we used RNA-seq data from over 500 HNSCC primary tumour samples from the TCGA to comprehensively compare the expression of genes across key cellular metabolic pathways between $\mathrm{HPV}+, \mathrm{HPV}-$, and normal-adjacent control tissues. Expression of a number of metabolic genes were significantly altered in HPV+ versus HPV- HNSCC. Specifically, genes involved in glycolysis were expressed at lower levels in HPV+ compared to HPV- HNSCC. In contrast, genes involved in the TCA cycle, oxidative phosphorylation, and $\beta$-oxidation exhibited higher expression in HPV+ samples compared to their HPV- counterparts. Importantly, we identified that low expression of multiple metabolic genes-SDHC, COX7A1, COX16, COX17, ELOVL6, GOT2, and SLC16A2-correlated with markedly improved patient survival in HPV+, but not HPV- HNSCC. The products of these genes could potentially be exploited as targets for therapeutic intervention. Furthermore, the low expression of these seven genes appears useful in predicting improved overall survival in HPV+ HNSCC and could serve as biomarkers of patient outcome.

\section{Results}

2.1. Expression of Pathway-specific Metabolic Genes Were Altered Between HPV+, HPV-, and Normal Control Samples from The TCGA HNSC Cohort

In order to identify differences in metabolic gene expression between HPV+ and HPV- HNSCC, we analyzed the TCGA Illumina HiSeq RNA expression dataset from the HNSC cohort for expression 
of 229 metabolic genes in central metabolic pathways (Supplementary Table S1). This clinical cohort is comprised of $73 \mathrm{HPV}+, 442 \mathrm{HPV-}$, and 43 normal control samples with available RNA-seq data. Significant differences were seen in a subset of genes in each pathway between HPV+ and HPV- HNSCC. In addition, significant changes were observed between either HPV+ HNSCC or HPV- HNSCC and normal control tissue. To simplify interpretation of these differences, we plotted the fraction of genes in each pathway that were significantly different for each pairwise comparison (Figure 1).

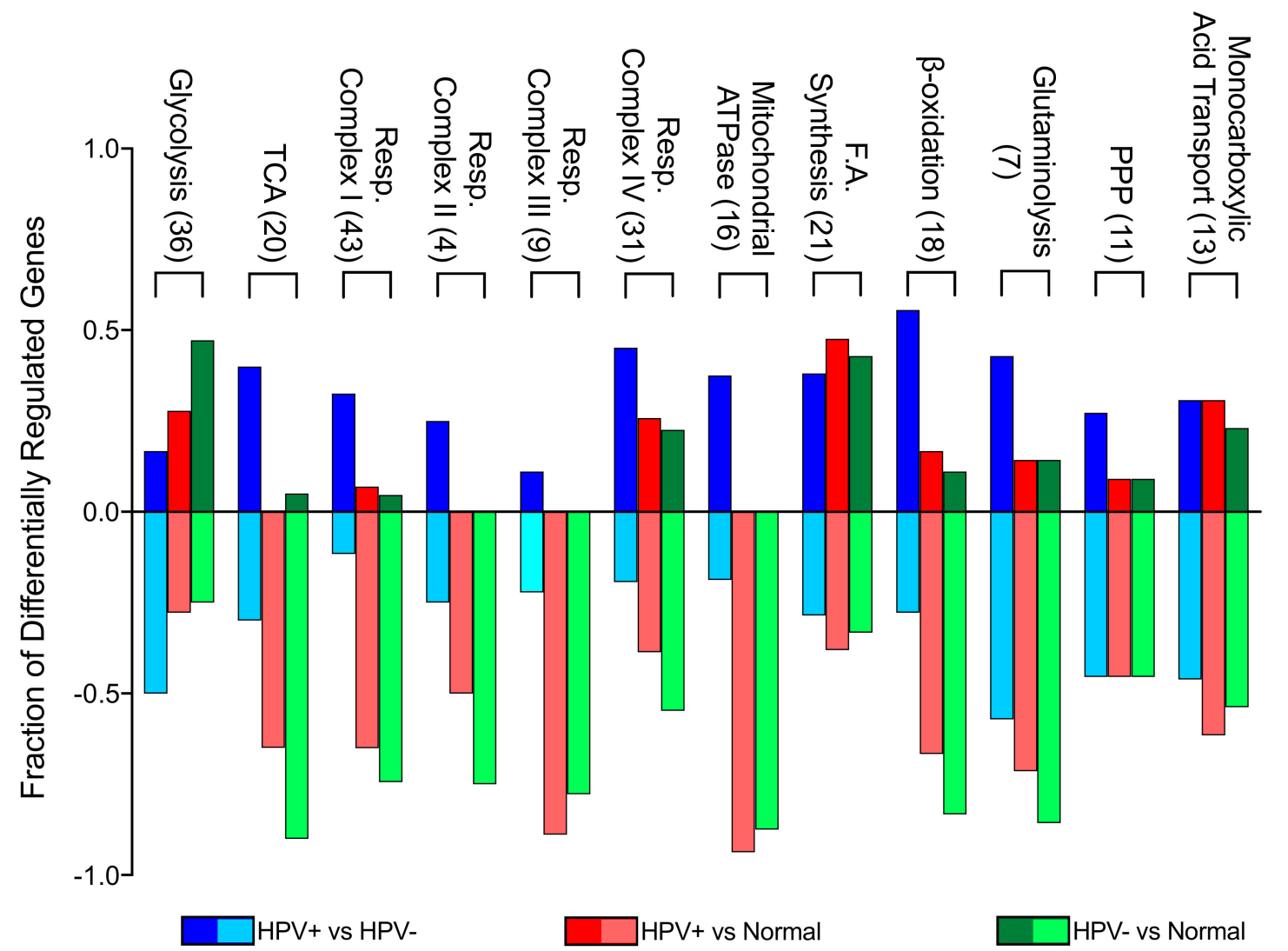

Figure 1. Genes differentially expressed between HPV-positive (HPV+) head and neck squamous cell carcinomas (HNSCC), HPV-negative (HPV-) HNSCC, and normal control tissues by metabolic pathway. The y-axis reflects the proportion of genes that are up or downregulated in a given pathway comparison. For example, the positive fraction of genes reflects the proportion of genes upregulated in the first group (e.g., HPV+) when compared to the second group (e.g., HPV-). The negative fraction of genes reflects the proportion of genes downregulated in the same comparison. Blue $=\mathrm{HPV}+$ tissue vs HPV- tissue comparison; Red = HPV + tissue vs normal control tissue comparison; Green = HPV- tissue vs normal control tissue comparison. Numbers in brackets denote total number of genes analyzed from each pathway. Abbreviations: TCA, tricarboxylic acid cycle; Resp., respiratory; F.A., fatty acid; PPP, pentose phosphate pathway.

This analysis illustrates that glycolytic genes in HPV- HNSCC tissue are more upregulated in comparison to normal tissue than in HPV+ HNSCC when compared to normal tissue. This is particularly evident between HPV+ HNSCC and HPV- HNSCC tissues, since most glycolytic genes are downregulated in HPV+ HNSCC when compared to HPV- HNSCC. However, genes involved in the TCA cycle, oxidative phosphorylation, and $\beta$-oxidation were downregulated in both HPV+ and HPVHNSCC in comparison to normal control tissue. This means that, despite differences in metabolic gene expression between HPV+ and HPV- HNSCC, the metabolism of both types of tumours could resemble the Warburg effect, with lower cellular respiration rates compared to normal control tissue. When compared to one another, HPV+ HNSCC had generally higher expression of these genes than HPV- HNSCC. Other metabolic pathways appeared to have a more similar split between upregulated 
and downregulated genes in all comparisons, suggesting that the presence of HPV may have minimal impact on transcriptionally mediated changes in these pathways. Overall, it appears that HPV+ HNSCC may be more reliant on cellular respiration than HPV- HNSCC.

\subsection{Low Expression of Genes Encoding Multiple Components of the Mitochondrial Electron Transport Chain} Are Associated with Improved Patient Survival in HPV + HNSCC

Tumour-associated metabolic alterations have functional consequences that impact disease progression, response to therapy, and patient survival [13]. We dichotomized the expression data for each of the 229 metabolic genes by median expression and calculated the impact of high versus low expression on overall patient survival for HPV+ HNSCC patients, as well as HPV- HNSCC patients (Supplementary Table S2). We identified seven genes that were significantly associated with patient survival in HPV+, but not HPV- HNSCC patients. These genes were SDHC, part of the mitochondrial respiratory complex II; COX7A1, COX16, and COX17, all part of the mitochondrial respiratory complex IV; ELOVL6, involved in fatty acid elongation; GOT2, involved in amino acid metabolism; and SLC16A2 (also known as MCT8), which encodes a thyroid hormone transporter. We performed a pathway enrichment analysis of our seven significant genes utilizing a PANTHER overrepresentation test which indicated that 5 of these 7 genes were significantly associated with the mitochondria $\left(p=5.10 \times 10^{-5}\right.$; FDR $=1.46 \times 10^{-2}$ ). These genes were SDHC, COX7A1, COX16, COX17, and GOT2. Detailed studies of the relative expression of each of these genes in HPV,$+ \mathrm{HPV}$ - and normal control tissue, as well as their association with overall patient survival are presented below.

Previous studies indicate that HPV+ HNSCC is more reliant on oxidative phosphorylation as an energy source than HPV- HNSCC [15]. Oxidative phosphorylation requires electron transport via mitochondrial cellular respiratory complexes I-IV [17]. Reduced expression of SDHC, which encodes a component of the mitochondrial cellular respiration complex II, correlated with increased HPV+ HNSCC patient survival (Figure 2).
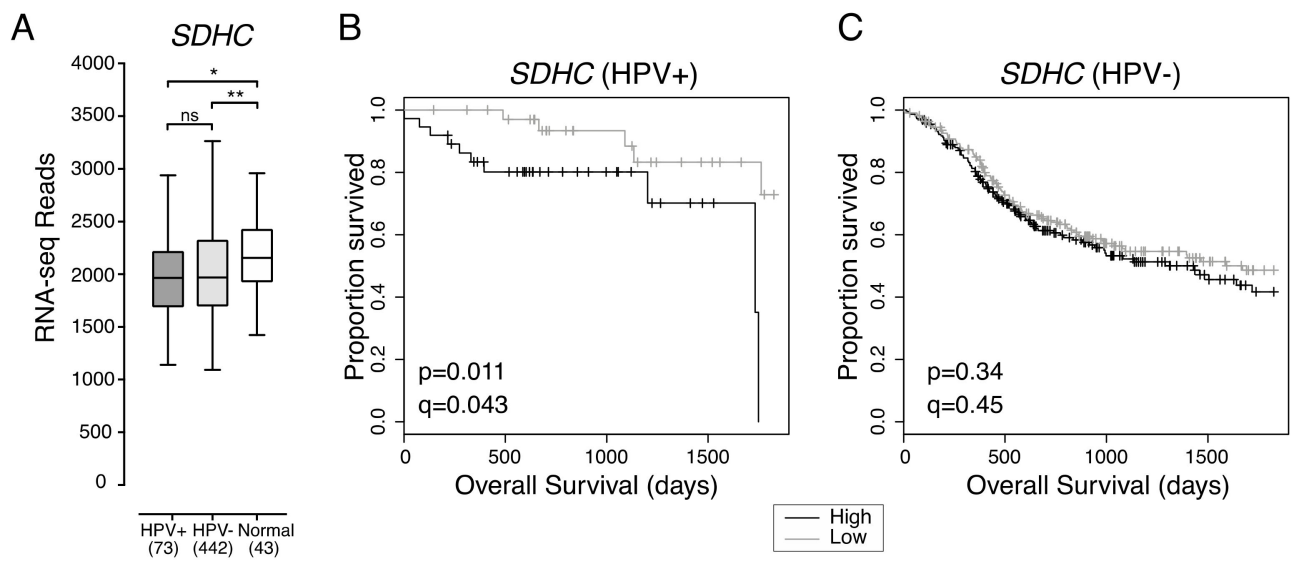

Figure 2. Low expression of SDHC is associated with favorable survival outcomes in HPV+ HNSCC. (A) Transcript levels of SDHC across all HNSCC tissues samples and normal control tissues. Bracketed numbers refer to the sample size of each group. Overall five-year survival outcomes in (B) HPV+ HNSCC and (C) HPV- HNSCC patients dichotomized by SDHC expression. $p=$ Two-sided log-rank test, $q=$ Benjamini-Hochberg FDR method. Gray = low transcript expression, Black = high transcript expression. ${ }^{*} p \leq 0.05,{ }^{* *} p \leq 0.01, \mathrm{~ns}$ (not significant).

Overall expression of SDHC was not significantly different between HPV+ and HPV- HNSCC, and both types of HNSCC expressed lower levels of SDHC than normal control tissue (Figure 2A). HPV+ HNSCC patients with tumours exhibiting low SDHC expression had better overall five-year survival outcomes than HPV+ HNSCC patients with tumours exhibiting high SDHC expression $(p=0.011, \mathrm{FDR}=0.043)$ (Figure 2B). However, SDHC expression was not correlated with improved patient survival in HPV- HNSCC ( $p=0.34$, FDR $=0.45)$ (Figure 2C). 
Consistent with the possibility that HPV+ HNSCCs are more reliant on cellular respiration than HPV- HNSCCs, three genes encoding components of the mitochondrial cellular respiration complex IV were also correlated with HPV+ HNSCC patient survival (Figure 3). These genes were COX7A1 and COX17, which encode structural components of complex IV, and COX16, whose product is involved in complex IV assembly.

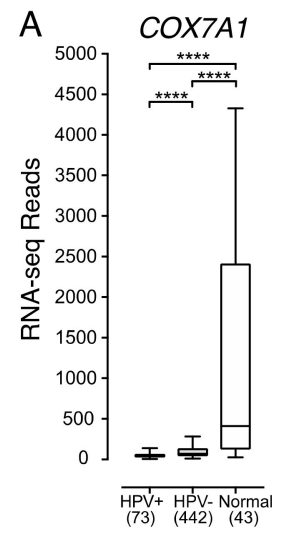

B

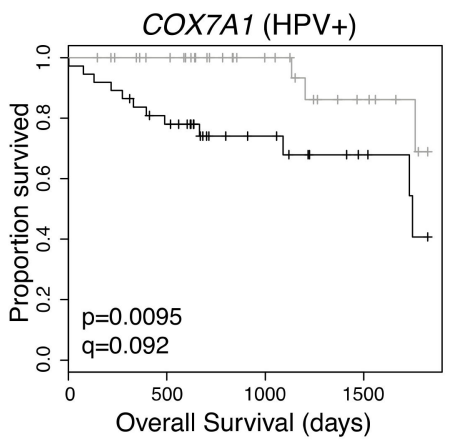

$E$

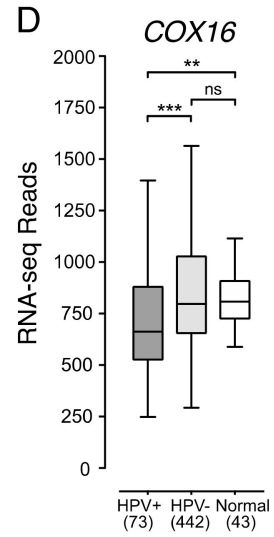

G

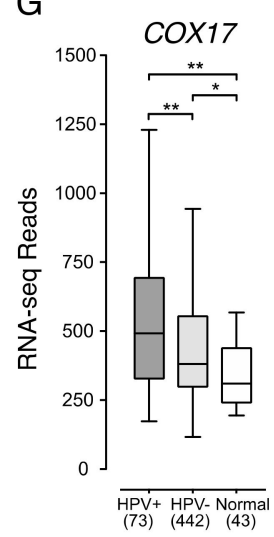

C

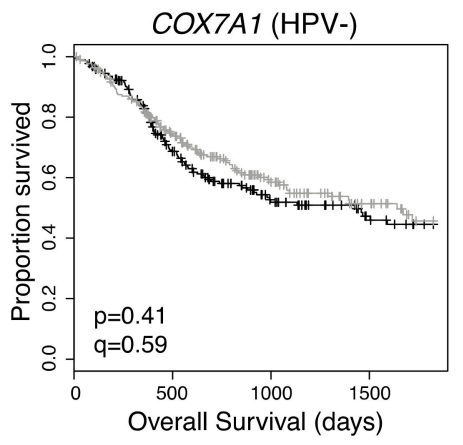

F

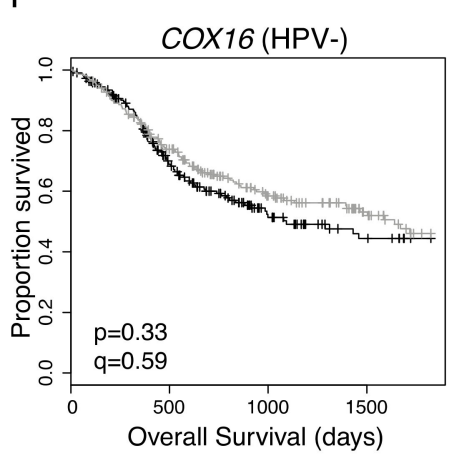

I

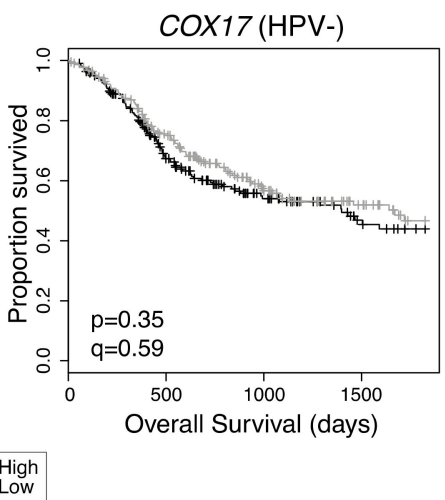

Figure 3. Low expression of three mitochondrial respiration complex IV genes in HPV+ HNSCC is associated with improved survival. Expression of (A) COX7A1, (D) COX16, and (G) COX17 in HNSCC tissues samples and normal control tissues. Overall 5-year survival outcomes in HPV+ HNSCC patients and HPV- HNSCC dichotomized by median (B,C) COX7A1 expression, (E,F) COX16 expression, and $(\mathbf{H}, \mathbf{I})$ COX17 expression. $p=$ Two-sided log-rank test, $q=$ Benjamini-Hochberg FDR method. Gray $=$ low transcript expression, Black $=$ high transcript expression. ${ }^{*} p \leq 0.05,{ }^{* *} p \leq 0.01,{ }^{* * *} p \leq$ $0.001{ }^{* * * *} p \leq 0.0001$, ns (not significant). 
COX7A1 expression was significantly lower in both HPV+ and HPV- HNSCC samples compared to normal control tissues (Figure 3A). In addition, HPV+ HNSCC had significantly lower expression of COX7A1 than HPV- HNSCC (Figure 3A). Overall survival of patients with HPV+ (Figure 3B) or HPV- HNSCC (Figure 3C) were dichotomized based on median COX7A1 expression. We found that low expression of $C O X 7 A 1$ was correlated with favourable survival outcomes in patients with HPV+ $(p=0.0095, \mathrm{FDR}=0.092)$ (Figure 3B), but not HPV- HNSCC $(p=0.41, \mathrm{FDR}=0.59)$ (Figure 3C).

Compared to normal control tissue, COX16 expression was lower in HPV+, but not in HPVHNSCC (Figure 3D). COX16 expression was also significantly lower in HPV+ compared to HPVHNSCC (Figure 3D). HPV+ and HPV- HNSCC samples were dichotomized based on median COX16 expression. Low levels of COX16 expression were correlated with improved survival in patients with HPV+ $(p=0.0080$, FDR $=0.092)$ (Figure 3E), but not in patients with HPV- HNSCC $(p=0.33$, $\mathrm{FDR}=0.59$ ) (Figure 3F).

In contrast to COX7A1 and COX16, COX17 expression was higher in HPV+ than HPV- HNSCC (Figure 3G). Expression of COX17 across HPV+ and HPV- HNSCC samples was significantly higher than in normal control tissues (Figure 3G). However, the same association between low expression of COX17 and better overall 5-year patient survival was observed for patients with HPV+ HNSCC $(p=0.00040$, FDR $=0.012)($ Figure $3 \mathrm{H})$, but not patients with HPV- HNSCC $(p=0.35$, FDR $=0.59)$ (Figure 3I).

\subsection{Low Expression of ELOVL6, Involved in Fatty Acid Synthesis, Is Associated with Better Overall Survival} in Patients with HPV+ HNSCC

ELOVL6 expression in HPV + HNSCC was not significantly different from HPV- HNSCC. However, both HPV+ and HPV- HNSCC had significantly lower overall levels of ELOVL6 expression than normal control tissues (Figure 4A). HPV+ HNSCC samples were dichotomized based on median ELOVL6 expression. HPV+ patients with tumours expressing low levels of ELOVL6 had significantly better five-year overall survival than patients with tumours expressing high levels of ELOVL6 ( $p=0.0040$, $q=0.084$ ) (Figure 4B). Reduced ELOVL6 expression was not correlated with altered survival in HPVHNSCC patients ( $p=0.34, q=0.83$ ) (Figure 4 C).

\subsection{Low Expression of GOT2, Involved in Amino Acid Metabolism, Is Associated with Better HPV+ HNSCC Patient Survival}

GOT2 expression was significantly lower in HPV+ than HPV- HNSCC or normal control tissues and significantly lower in HPV- HNSCC than normal control tissues (Figure 4D). The high normalized RNA-seq read levels for GOT2 suggest that it is abundantly expressed in normal head and neck tissues. HPV+ HNSCC samples were dichotomized based on median GOT2 expression. Low expression of GOT2 was associated with better five-year overall survival outcomes in patients with HPV+ HNSCC $(p=0.012, q=0.086$; Figure 4E). Although low GOT2 expression appeared to be significantly correlated with favourable patient survival in HPV- HNSCC $(p=0.029$; Figure $4 \mathrm{~F})$, it lost its significance after correcting for FDR $(q=0.20)$.

2.5. Low Expression of SLC16A2, a Thyroid Hormone Transporter, in HPV+ HNSCC Is Associated with Better Overall Survival

Increased expression of the monocarboxylic acid transporter family member, SLC16A1 (MCT1) was recently reported to be associated with poor survival outcomes in HNSCC [15]. Although, expression of SLC16A1 was significantly higher than normal head and neck tissues for both HPV+ and HPVHNSCC, and expression of SLC16A1 was higher in HPV- HNSCC than HPV+ HNSCC, the impact of differential expression of SLC16A1 on overall survival in either HPV+ or HPV- HNSCC was not significant $(p>0.05)$. Of the various family members, only expression of SLC16A2 (MCT8), whose main function is thyroid hormone transport, appeared to be associated with altered overall survival (Figure 4G-I). 
Expression of SLC16A2 was significantly lower in HPV+ HNSCC when compared to either HPVHNSCC or normal control tissues (Figure 4G). HPV+ HNSCC samples were dichotomized based on median SLC16A2 expression. Again, low expression of SLC16A2 was associated with improved patient survival in HPV+ HNSCC patients $(p=0.0036$, FDR $=0.047$ ) (Figure $4 \mathrm{H})$, but not in patients with HPV$\operatorname{HNSCC}(p=0.26, \mathrm{FDR}=0.48)($ Figure $4 \mathrm{I})$.

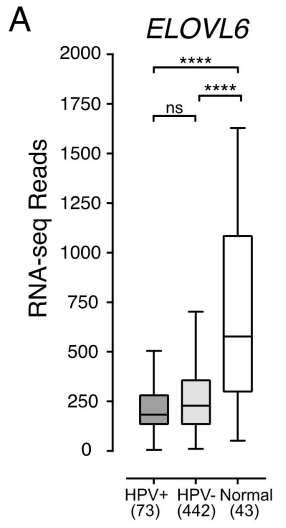

D
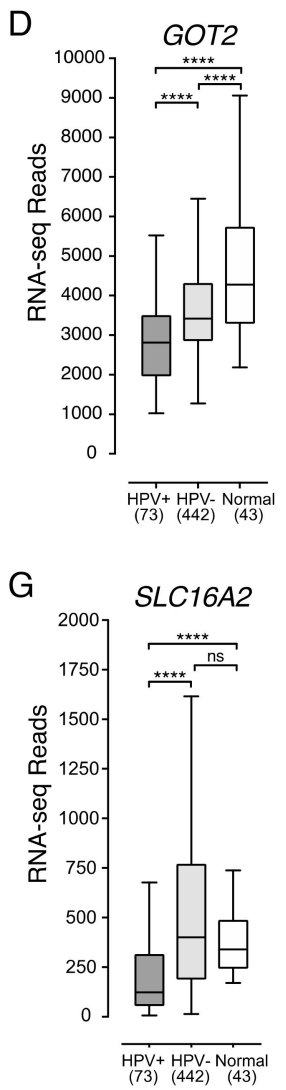

B

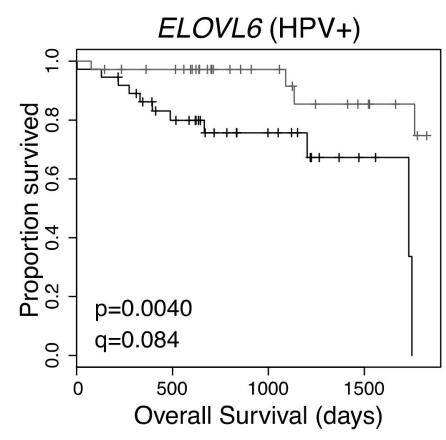

$\mathrm{E}$

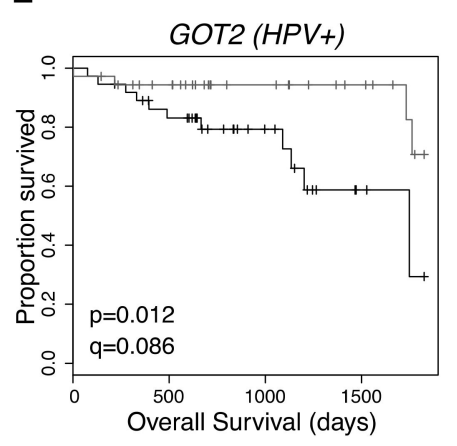

$\mathrm{H}$

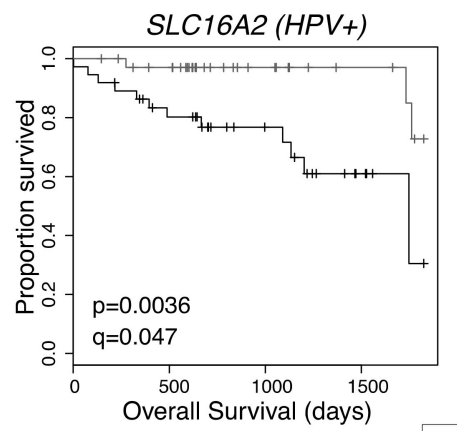

C

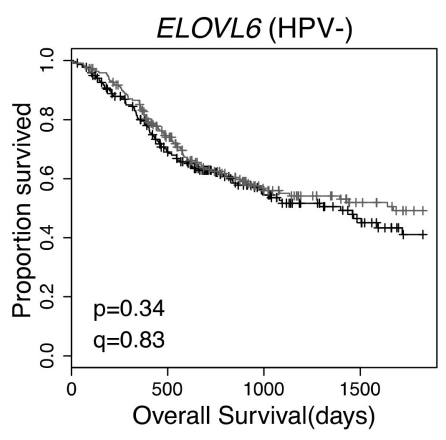

$\mathrm{F}$

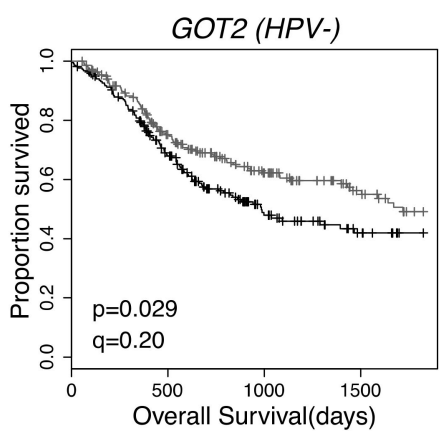

I

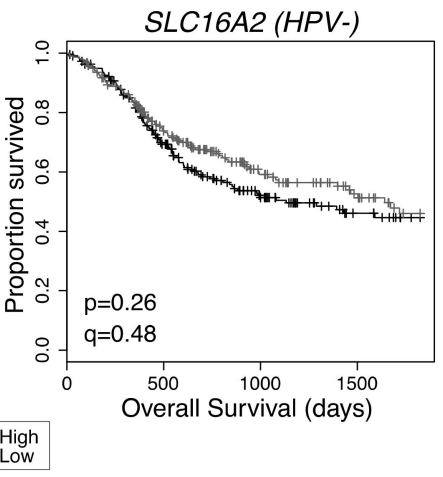

Figure 4. Low expression of ELOVL6, GOT2 and SLC16A2 is associated with improved patient survival in HPV+ HNSCC. Expression of (A) ELOVL6, (D) GOT2, and (G) SLC16A2 in HPV+, HPV- HNSCC tissue samples and normal control tissues. Overall five-year survival outcomes in HPV+ HNSCC and HPV- HNSCC patients dichotomized by median (B,C) ELOVL6 expression, (E,F) GOT2 expression, and $(\mathbf{H}, \mathbf{I})$ SLC16A2 expression. $p=$ Two-sided log-rank test and $q=$ Benjamini-Hochberg FDR method. Gray $=$ low transcript expression, Black $=$ high transcript expression. ${ }^{* * * *} p \leq 0.0001$, ns (not significant). 
2.6. COX16, COX17, and SLC16A2 Are Independently Correlated with Favourable Survival Outcomes in HPV + HNSCC

To determine the extent that each of the HPV+ HNSCC survival-associated genes could influence patient outcomes, we generated a hazard ratio (HR) for each gene and a variety of clinical variables by univariate analysis (Table 1). Each HR describes the relative increase in risk of death for the first variable $x$ vs $y$ [18]. As expected, the HR for each metabolic gene was significantly below 1, indicating a greatly reduced risk of death. In contrast, a comparison of the oral cavity vs the oropharynx subsites for HPV+ HNSCC generated a hazard ratio of 2.82, indicating that HPV+ HNSCC in the oral cavity is associated with a $2.82 \mathrm{x}$ increased risk of mortality compared to oropharynx.

Table 1. Univariate and multivariate analysis of the association of clinical variables and expression of metabolic genes with overall survival in HPV+ HNSCC.

\begin{tabular}{|c|c|c|c|c|c|}
\hline & \multirow{2}{*}{ Variables } & \multirow{2}{*}{$\begin{array}{c}\text { Univariate } \\
\text { HR (95\% CI) }\end{array}$} & \multicolumn{3}{|c|}{ Multivariate } \\
\hline & & & P value & HR (95\% CI) & P value \\
\hline Sex & Male vs Female & $0.81(0.18-3.62)$ & 0.78 & & \\
\hline Age & per every additional year & $0.99(0.94-1.04)$ & 0.74 & & \\
\hline \multirow{3}{*}{ Subsite } & Oral cavity vs Oropharynx & $2.82(1.02-7.80)$ & 0.045 & $13.59(2.67-69.11)$ & 0.002 \\
\hline & Larynx vs Oropharynx & $1.52 \times 10^{-8}(0-$ Inf $)$ & 1.00 & $3.67 \times 10^{-10}(0-$ Inf $)$ & 1.00 \\
\hline & Hypopharynx vs Oropharynx & $1.57 \times 10^{-8}(0-\operatorname{Inf})$ & 1.00 & $1.10 \times 10^{-8}(0-$ Inf $)$ & 1.00 \\
\hline T Stage & T3-T4 vs T1-T2 & $1.03(0.36-2.91)$ & 0.96 & & \\
\hline N Stage & $\mathrm{N} 2 \mathrm{~b}-\mathrm{N} 3$ vs N0-N2a & $0.41(0.14-1.19)$ & 0.10 & & \\
\hline Overall Stage & IV vs I-III & $0.76(0.26-2.24)$ & 0.62 & & \\
\hline HPV Type & $33,35,56$ vs 16 & $3.33(1.14-9.78)$ & 0.028 & $16.88(3.24-87.88)$ & 0.0008 \\
\hline COX16 & Low vs High Expression & $0.19(0.05-0.72)$ & 0.015 & $0.059(0.009-0.39)$ & 0.003 \\
\hline COX17 & Low vs High Expression & $0.13(0.03-0.47)$ & 0.002 & $0.03(0.003-0.35)$ & 0.005 \\
\hline COX7A1 & Low vs High Expression & $0.22(0.06-0.77)$ & 0.018 & $0.25(0.04-1.56)$ & 0.14 \\
\hline ELOVL6 & Low vs High Expression & $0.17(0.04-0.65)$ & 0.009 & & \\
\hline GOT2 & Low vs High Expression & $0.24(0.07-0.79)$ & 0.019 & & \\
\hline SDHC & Low vs High Expression & $0.23(0.07-0.77)$ & 0.018 & & \\
\hline SLC16A2 & Low vs High Expression & $0.17(0.04-0.63)$ & 0.008 & $0.07(0.01-0.37)$ & 0.002 \\
\hline
\end{tabular}

As the contribution of these genes to overall survival might not be independent of one another, we also analyzed the relationship between survival and gene expression for all survival-associated metabolic genes and clinical variables concurrently by multivariate analysis (Table 1). The hazard ratios for COX16, COX17, and SLC16A2 remained significant, indicating that low expression of each of these genes is a significant, and potentially independent, contributor to overall survival. COX7A1 had a minor contribution to survival in this model. The multivariate model also included subsite (oral cavity vs. oropharynx) and HPV type as significant contributing factors to survival as previously reported in the literature [19-22].

To test whether concurrent low expression of these genes had an additive effect on survival, we stratified the HPV+ HNSCCs into groups, based on high expression or low expression for a combination of any two of these seven survival-associated genes. When survival of HPV+ HNSCC patients with low expression of both COX16 and COX17 in their tumours was compared to survival of patients with high expression of both genes, survival was significantly greater in the COX16 and COX17 double low expression group $(p=0.0015)$ (Figure 5A). In patients with low expression of both COX16 and SLC16A2, survival was virtually 100\% until approximately 4.75 years and significantly better ( $p=0.0021$ ) than samples expressing high levels of both genes (Figure 5B). In patients with low expression of both COX17 and SLC16A2 (Figure 5C), survival was 100\%, which was significantly higher than patients expressing high levels of both COX17 and SLC16A2 ( $p=0.00027$; Figure 5C). 
A

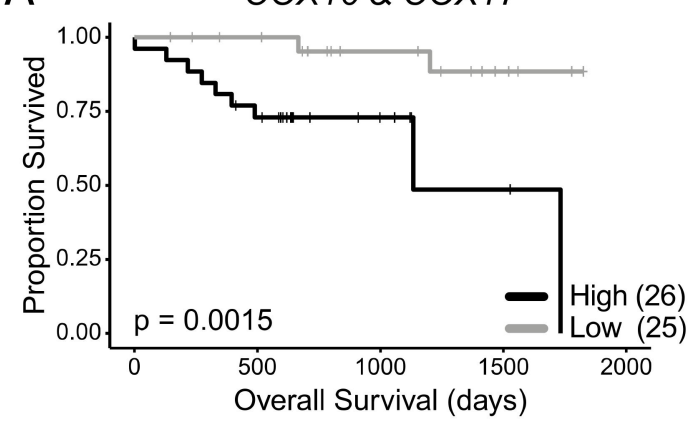

B

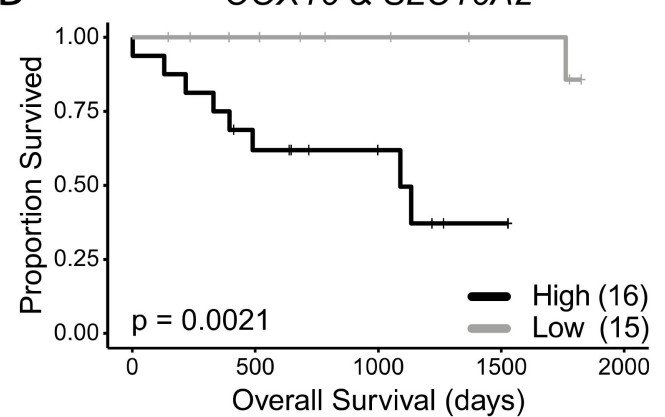

C

COX17 \& SLC16A2

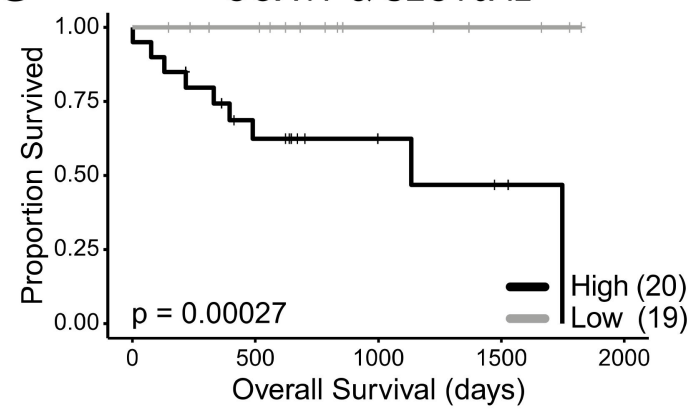

Figure 5. HPV+ HNSCC patient survival stratified by double low or double high expression of survival-associated metabolic genes. (A) COX16 and COX17, (B) COX16 and SLC16A2, (C) COX17 and SLC16A2. Comparisons made with a two-sided log-rank test. Gray $=$ low transcript expression, Black = high transcript expression. Bracketed value indicates number of HPV+ HNSCCs with double high or double low expression for genes of interest.

Supplementary Figure S1 shows that there was no significant correlation between the expression of SLC16A2 and COX16 or SLC16A2 and COX17. This provides further evidence that the improved survival associated with low expression for each of these genes may occur independently of one another. Additionally, the multivariate analysis indicates that COX16 and COX17 independently contribute to survival despite the correlation between these two genes (Supplementary Figure S1).

\section{Discussion}

Our analysis identified many changes in expression of metabolism-associated genes between HPV+ and HPV- HNSCC when compared to normal control tissues. The expression of seven genes was predictive of survival for HPV+ HNSCC patients. In each case, reduced expression correlated with improved survival, suggesting that reduced tumour cell metabolism is prognostically favorable. None of these genes were associated with altered survival in HPV- HNSCC, reinforcing the concept that HPV+ and HPV- HNSCC are distinct tumour entities [7-9,23]. This is not unexpected, as E6 from HPV16 and HPV18 can increase the expression of mitochondrial cellular respiration genes in a head and neck cancer cell line [24], which matches our observation of increased expression of these genes in HPV+ HNSCCs when compared to HPV- HNSCCs. In addition, E6 and E7 may also be responsible for perturbing glycolysis in HPV+ cervical cancer cells $[25,26]$, which could explain our observation of increased expression of glycolytic genes in HPV+ HNSCC as compared to normal control tissues. Interestingly, most of the survival-associated genes we identified in our study can be inhibited by small molecule inhibitors as outlined below.

As shown in our results, limiting SDHC may serve as a unique target in virally transformed HPV+ HNSCCs. SDHC encodes part of mitochondrial respiratory complex II, for which a few selective inhibitors exist. $\alpha$-tocopheryl succinate ( $\alpha$-TOS) is a vitamin $E$ analogue, which has selective growth inhibitory properties for some human cancer cells [27]. $\alpha$-TOS can induce apoptosis by increasing 
the levels of reactive oxidative species (ROS), triggering stress response pathways [27]. $\alpha$-TOS is also effective at inhibiting tumour growth [28] in in vivo xenograft mouse models. Interestingly, $\alpha$-TOS inhibited growth of several HNSCC cell lines in vitro and in vivo [29]. Given that all of these experiments were done using HPV- HNSCC, $\alpha$-TOS may be even more toxic to HPV+ HNSCCs based on the correlation between SDHC expression and HPV+ HNSCC survival outcomes we observed.

Specific small molecule inhibitors for both the COX7A1 and COX16 gene products have not yet been identified. However, as both are part of mitochondrial respiratory complex IV, it is possible that the complex IV inhibitors ADDA 5 [30] and tetrathiomolybdate [31] could prove useful to phenocopy any metabolic effects associated with low gene expression, promoting enhanced survival in HPV+ HNSCC. It is also important to note that COX16 is an inhibitor of p53 activity, which means that non-mitochondrial functions of COX16 should not be discounted [32]. E6 has been shown to inhibit expression of COX16 [33], which may contribute to the lower levels observed in HPV+ versus HPV- HNSCC (Figure 3D). MitoBloCK-6 is an inhibitor of mitochondrial respiratory complex IV that specifically targets the COX17 protein [34]. Whether inhibition of cellular respiration is less effective in HPV- HNSCCs because they are already more oxidatively stressed than HPV+ HNSCCs [35], perhaps as a result of being less adapted to utilize cellular respiration, is an open question.

Two inhibitors of ELOVL6 were able to reduce the fatty acid composition of hepatocytes and the liver in a murine model of obesity [36,37], but the effects of these compounds on cancer cells have not been explored. Another potential druggable target to influence ELOVL6 expression is ATP citrate lyase (ACLY), which has a wide variety of inhibitors [38]. Expression of ELOVL6 has been shown to decrease concurrently with ACLY inhibition [39]. Whether ELOVL6 inhibition would reduce the growth of HPV+ HNSCC cell lines remains to be examined.

In our study, we found that low expression of GOT2 was associated with statistically significant survival in both groups $(\mathrm{p}<0.05)$. However, only expression of GOT2 in our HPV+ HNSCC group met the FDR cut-off of $q=0.1$. This means that while GOT2 may be important for survival outcomes in both HPV+ and HPV- HNSCC, it is likely that it has a more substantial contribution to patient survival in HPV+ HNSCC. In breast cancer, sensitivity to a nucleotide synthesis inhibitor, methotrexate, has been linked to high GOT2 expression [40]. This is likely due to the function of GOT2 in providing aspartate for nucleotide biosynthesis [40]. It is possible that HPV+ HNSCCs, or potentially any HNSCCs expressing high levels of GOT2, may be sensitive to methotrexate, but this remains to be explored.

SLC16A2 encodes a plasma membrane T3/T4 transporter. Once inside the cell, T3/T4 can bind nuclear and mitochondrial-localized thyroid hormone receptors, which are key regulators of mitochondrial biogenesis [41]. As HPV+ HNSCC may be more reliant on cellular respiration than HPV- HNSCC, it is possible that inhibiting SLC16A2-mediated thyroid hormone transport across the plasma membrane could preferentially inhibit ATP generation in HPV+ HNSCCs. Some tyrosine kinase inhibitors (TKIs), such as sunitinib, imatinib, dasatinib, and bosutinib, may inhibit SLC16A2 [42]. These TKIs are already employed to treat a wide variety of cancers and are being evaluated for the treatment of HNSCC [43]. As such, they may be especially suitable for the treatment of HPV+ HNSCCs expressing SLC16A2 at high levels. We extracted data from our previous study of 27 HNSCC cell lines (6 HPV+ and 21 HPV- HNSCC cell lines) examining the effects of a variety of agents on cell growth and proliferation, including the TKI inhibitors mentioned above [44]. Of the TKIs tested, dasatinib was selectively cytotoxic to HPV+, but not HPV- HNSCC cell lines (Supplementary Figure S2), suggesting that it could be used as a treatment for HPV+ HNSCC that expresses high levels of SLC16A2. A flavonoid, silychristin, also inhibits SLC16A2 [45], but has not been studied in cancer models. Other antithyroid hormones used to treat hyperthyroidism, such as carbimazole, methimazole, and potassium perchlorate, could preferentially inhibit HPV+ HNSCC by mimicking inhibition of the SLC16A2 transporter. In one study, methimazole was used to experimentally treat patients with end-stage solid tumours and resulted in improved survival [46]. High levels of thyroid hormone can promote proliferation of some cancers [47], and thyroid hormone mimetics which function as 
antagonists, such as tetraiodothyroacetic acid (tetrac) and triiodothyroacetic acid (triac) appear to exhibit an antiproliferative effect on breast cancer [47] and T cell lymphomas [48].

While our univariate analysis of all seven genes confirmed that their expression was significantly correlated with survival, our multivariate analysis indicated that COX16, COX17, and SLC16A2 were independently associated with overall survival. This suggested that the collective changes in the expression of these three genes could be a powerful predictor of clinical outcome. This was supported by our observation that the overall survival for the group of patients exhibiting simultaneously low expression of any two of these genes was far better than those simultaneously expressing high levels. Thus, expression of these genes may have prognostic utility. Furthermore, COX16, COX17, and SLC16A2 may represent attractive therapeutic targets for HPV+ HNSCC that warrant further exploration, especially considering that treatment with specific inhibitors may phenocopy the effects of low expression of these metabolic genes.

It is important to be cognizant of the limitations to this kind of study. One limitation to this study was the lack of protein data in the TCGA to corroborate our HPV+ HNSCC mRNA expression data. This is an important consideration, as levels of protein expression do not necessarily mirror mRNA expression [49]. As with any high throughput dataset, batch effects that result from processing could be reflected in the data [50]. In addition, the RNA-seq data contained within the TCGA reflects average mRNA expression within the whole tumour and does not identify expression differences between the various tumour cells as could be obtained from single-cell RNA sequencing platforms [51,52]. However, the bulk of the tissue that was sequenced is of tumour origin [52]. Also, it is important to be aware that the TCGA contains HNSCC data from a single, albeit high quality, cohort and it would be useful to validate these genes of interest in other cohorts in the future. Finally, the concept of biomarker identification itself has its own caveats. Specifically, all of the survival-associated genes we identified in this study are only correlated with survival, which does not equal causation [53]. In addition, as with all studies of this type, there exists the possibility that these correlations are due to chance or occur as the result of another confounder [53]. However, despite these limitations, the seven metabolic genes identified in this study provide an interesting starting point for considering the metabolic differences between HPV+ and HPV- HNSCC as new prognostic markers or potential targets for therapy.

\section{Materials and Methods}

\subsection{Data Collection}

Level 3 RNA-seq by Expectation Maximization normalized Illumina HiSeq RNA expression data (build 2016012800) for the TCGA HNSC cohort, was downloaded from the Broad Genome Data Analysis Centers Firehose server (https://gdac.broadinstitute.org/). Patient survival data for the TCGA HNSC cohort, as reported by the Pan-Cancer Atlas [54], was downloaded from: https://www.cell.com/ cms/10.1016/j.cell.2018.02.052/attachment/f4eb6b31-8957-4817-a41f-e46fd2a1d9c3/mmc1.xlsx.

\subsection{RNA Expression Comparisons}

RNA-seq by Expectation Maximization normalized expression data for the TCGA HNSC cohort was extracted and analyzed as described previously [23]. Briefly, primary patient samples with known HPV status were manually grouped as HPV+, HPV-, or normal-adjacent control tissue based on other previously published datasets [21,35]. In these datasets, HPV status was assigned by aligning RNA-seq reads for the HPV oncogenes expressed in the tumours to the different high risk HPV types. This resulted in $73 \mathrm{HPV}+, 442 \mathrm{HPV}-$, and 43 normal-adjacent control samples with data available for gene expression comparisons. Note that all HPV+ samples had high risk HPV as follows: HPV16 (61 samples), HPV33 (8 samples), HPV35 (3 samples), and HPV56 (1 sample). The five-number summary, mean, and pairwise statistical tests were calculated using $R$ (version 3.4.0) for all 229 metabolic genes analyzed (see Supplementary Table S1). These 229 genes were manually selected (Supplementary Table S1) as they are involved in eight central cellular metabolic pathways or processes, 
of which cellular respiration was then separated into its respective complexes. The number of genes examined from each pathway was as follows: glycolysis, 36 genes (adapted from GO:0061621 and [55]); TCA cycle, 20 genes (adapted from GO:0006099 and [56]); mitochondrial respiratory complex I, 43 genes (adapted from GO:0045333, GO:0046043 and [57]); mitochondrial respiratory complex II, 4 genes (adapted from GO:0045333, GO:0046043 and [58]); mitochondrial respiratory complex III, 9 genes (adapted from GO:0045333, GO:0046043 and [59,60]); mitochondrial respiratory complex IV, 31 genes (adapted from GO:0045333, GO:0046043 and [61]); mitochondrial ATPase, 16 genes (adapted from GO:0046043 and [62]); fatty acid synthesis, 21 genes (adapted from GO:0019368, GO:0046949, GO: 0006629 and [63-66]); $\beta$-oxidation, 18 genes (adapted from GO:0003995, GO:0003985, GO: 0004300 and [67]); glutaminolysis, 7 genes (adapted from GO:0004069, GO:0004352, GO: 0004359, GO: 0004021 and [68]); pentose phosphate pathway, 11 genes (GO:0006098 and [69]); monocarboxylic acid transport (MCT) family, 13 genes (adapted from GO:0008028 and [15]). Boxplot comparisons of gene expression were made with GraphPad Prism v7.0 (Graphpad Software, Inc., San Diego, California, USA). For the boxplots, center lines show the medians, box limits indicate the 25th and 75th percentiles, and whiskers extend 1.5 times the interquartile range from the 25 th and 75 th percentiles. P-values were assigned using a two-tailed non-parametric Mann-Whitney U test using Graphpad Prism. Bivariate analysis for selected genes was performed through $R$ (version 3.4.0) using the Spearman rank correlation coefficient. The proportion of genes in each pathway that were up or downregulated among each comparison was represented in a bar graph and was calculated as follows: number of genes upregulated (or downregulated) in a comparison (e.g., HPV+ HNSCC vs HPV- HNSCC) divided by the total number of genes in that pathway. The proportion of downregulated genes were represented as a negative value.

\subsection{Survival Analysis}

Five-year overall survival outcomes were compared in both HPV+ and HPV- subsets of HNSCC patients dichotomized by median expression for all metabolic genes listed in Supplementary Table S1. Log-rank statistical p-values were calculated for each Cox survival model. The derived log-rank p-values for all tested genes (listed in Supplementary Table S2) were assessed for significance after correcting for false discovery rate (FDR) using the Benjamini-Hochberg method, and an FDR threshold of 0.1 was set for significance. Univariate analysis was performed through $\mathrm{R}$ (version 3.4.0) based on a Cox Proportional Hazard Model using the survival package (version 2.41-3). Stepwise bidirectional multivariate analysis was then carried out with clinical variables (sex, age, subsite, $\mathrm{T}$ stage, $\mathrm{N}$ stage, Overall stage, and HPV type), and SDHC, COX7A1, COX16, COX17, ELOVL6, GOT2, and SLC16A2 expression-low expression of these 7 genes were found to be statistically correlated with improved survival after univariate analysis. The p-values derived from the Wald test on survival coefficients were reported for investigated variables. Furthermore, a second set of survival outcomes were determined to compare HPV+ tumours expressing low levels of each combination of genes that were significantly correlated with improved survival after multivariate analysis—COX16, COX17, and SLC16A2.

\subsection{Gene Enrichment Analysis}

We performed a gene enrichment analysis on our seven survival-associated genes using the Go Enrichment Analysis feature on http://geneontology.org [70,71]. This analysis is powered by PANTHER14.1 (PANTHER Overrepresentation Test) using the "GO cellular component complete" annotation data set with a Fisher's exact test followed by a calculation of false discovery rate (cutoff $=$ FDR $P<0.05)$ to determine statistical significance [72].

\subsection{Analysis of Differential Cell Line Sensitivity to Tyrosine Kinase Inhibitors Based on HPV Status}

B-scores (mean \pm SEM) reflecting drug activity were extracted from a previously conducted high throughput drug screen using 27 HNSCC cell lines [44]. The average B-scores for the indicated 
tyrosine kinase inhibitors (TKIs) was calculated for the 6 HPV+ and 21 HPV- HNSCC lines and plotted (Supplementary Figure S2).

\section{Conclusions}

In summary, our analysis of HNSCC TCGA data stratified by HPV status indicated that the metabolic profile of HPV+ and HPV- HNSCC are strikingly different. HPV- HNSCCs may utilize glycolysis to a greater extent than HPV+ HNSCCs, while HPV+ HNSCCs may be more reliant on the TCA cycle, cellular respiration, and $\beta$-oxidation than HPV- HNSCCs. Despite this difference, both types of HNSCCs likely exhibit far less cellular respiration than normal head and neck tissues, consistent with a cancer-associated Warburg phenotype [73]. Importantly, expression of genes involved in mitochondrial complex II and mitochondrial complex IV were associated with survival for HPV+ HNSCC patients. Namely, low expression of SDHC, COX7A1, COX16, or COX17 was associated with better survival outcomes. Low expression of ELOVL6, involved in fatty acid elongation; GOT2, involved in amino acid metabolism; and SLC16A2, involved in thyroid hormone transport, were also all associated with better survival outcomes in HPV+ HNSCC patients. However, of these genes, only COX16, COX17 and SLC16A2 were independently correlated with survival outcomes according to our multivariate analysis. Importantly, COX16, COX17, and SLC16A2 were associated with near 100\% survival in all patients with low expression of any two of these genes. The products of these genes may represent useful new therapeutic targets for HPV+ HNSCC, as inhibition of their functions could phenocopy the metabolism of those tumours with low levels of metabolic gene expression, leading to improved survival in HPV+ HNSCC patients.

Supplementary Materials: The following are available online at http://www.mdpi.com/2072-6694/12/1/253/s1, Figure S1: Correlation plots of independently significant genes identified by multivariate analysis, Figure S2: Tyrosine kinase inhibitor activity in 27 HNSCC cell lines based on HPV status, Table S1: Metabolic pathway gene expression, Table S2: Survival curve statistics.

Author Contributions: Writing_Original Draft: M.A.P. and J.S.M.; Writing—Review and Editing: M.A.P., J.S.M., S.F.G., F.G., M.J.D., P.Y.F.Z., H.M., J.W.B., and A.C.N.; Conceptualization: J.S.M., M.A.P., S.F.G., J.W.B. and A.C.N.; Software: S.F.G. and F.G.; Formal Analysis: M.A.P., S.F.G., F.G., M.J.D., P.Y.F.Z., H.M. and J.S.M.; Supervision: J.S.M., J.W.B. and A.C.N. Visualization: M.A.P. and S.F.G. All authors have read and agreed to the published version of the manuscript.

Funding: This work was supported by grants provided by the Canadian Institutes of Health Research to J.S.M./A.C.N. (MOP\#148689) and A.C.N. (MOP\#340674). A.C.N. was supported by the Wolfe Surgical Research Professorship in the Biology of Head and Neck Cancers Fund. S.F.G. was supported from a Cancer Research and Technology Transfer studentship. M.A.P. was supported by a studentship from the Natural Sciences and Engineering Research Council of Canada and from the Western University Schulich School of Medicine and Dentistry.

Conflicts of Interest: The authors declare no conflict of interest.

\section{References}

1. Bray, F.; Ferlay, J.; Soerjomataram, I.; Siegel, R.L.; Torre, L.A.; Jemal, A. Global cancer statistics 2018: GLOBOCAN estimates of incidence and mortality worldwide for 36 cancers in 185 countries. CA Cancer J. Clin. 2018, 68, 394-424. [CrossRef]

2. Ferlay, J.; Colombet, M.; Soerjomataram, I.; Mathers, C.; Parkin, D.M.; Piñeros, M.; Znaor, A.; Bray, F. Estimating the global cancer incidence and mortality in 2018: GLOBOCAN sources and methods. Int. J. Cancer 2018, 144, 1941-1953. [CrossRef]

3. De Martel, C.; Plummer, M.; Vignat, J.; Franceschi, S. Worldwide burden of cancer attributable to HPV by site, country and HPV type. Int. J. Cancer 2017, 141, 664-670. [CrossRef]

4. Herrero, R.; Castellsagué, X.; Pawlita, M.; Lissowska, J.; Kee, F.; Balaram, P.; Rajkumar, T.; Sridhar, H.; Rose, B.; Pintos, J.; et al. Human papillomavirus and oral cancer: The International Agency for Research on Cancer multicenter study. J. Natl. Cancer Inst. 2003, 95, 1772-1783. [CrossRef]

5. Michmerhuizen, N.L.; Birkeland, A.C.; Bradford, C.R.; Brenner, J.C. Genetic determinants in head and neck squamous cell carcinoma and their influence on global personalized medicine. Genes Cancer 2016, 7, 182-200. 
6. Chaturvedi, A.K.; Engels, E.A.; Pfeiffer, R.M.; Hernandez, B.Y.; Xiao, W.; Kim, E.; Jiang, B.; Goodman, M.T.; Sibug-Saber, M.; Cozen, W.; et al. Human papillomavirus and rising oropharyngeal cancer incidence in the United States. J. Clin. Oncol. 2011, 29, 4294-4301. [CrossRef]

7. Seiwert, T.Y.; Zuo, Z.; Keck, M.K.; Khattri, A.; Pedamallu, C.S.; Stricker, T.; Brown, C.; Pugh, T.J.; Stojanov, P.; Cho, J.; et al. Integrative and comparative genomic analysis of HPV-positive and HPV-negative head and neck squamous cell carcinomas. Clin. Cancer Res. 2015, 21, 632-641. [CrossRef]

8. Worsham, M.J.; Chen, K.M.; Ghanem, T.; Stephen, J.K.; Divine, G. Epigenetic modulation of signal transduction pathways in HPV-associated HNSCC. Otolaryngol. Head Neck Surg. 2013, 149, 409-416. [CrossRef]

9. Gameiro, S.F.; Ghasemi, F.; Barrett, J.W.; Koropatnick, J.; Nichols, A.C.; Mymryk, J.S.; Maleki Vareki, S. Treatment-naïve HPV+ head and neck cancers display a T-cell-inflamed phenotype distinct from their HPVcounterparts that has implications for immunotherapy. Oncoimmunology 2018, 7, 1-14. [CrossRef]

10. Fakhry, C.; Westra, W.H.; Li, S.; Cmelak, A.; Ridge, J.A.; Pinto, H.; Forastiere, A.; Gillison, M.L. Improved survival of patients with human papillomavirus-positive head and neck squamous cell carcinoma in a prospective clinical trial. J. Natl. Cancer Inst. 2008, 100, 261-269. [CrossRef]

11. Weller, M.A.; Ward, M.C.; Berriochoa, C.; Reddy, C.A.; Trosman, S.; Greskovich, J.F.; Nwizu, T.I.; Burkey, B.B.; Adelstein, D.J.; Koyfman, S.A. Predictors of distant metastasis in human papillomavirus-associated oropharyngeal cancer. Head Neck 2017, 39, 940-946. [CrossRef]

12. Lunt, S.Y.; Vander Heiden, M.G. Aerobic Glycolysis: Meeting the Metabolic Requirements of Cell Proliferation. Annu. Rev. Cell Dev. Biol. 2011, 27, 441-464. [CrossRef]

13. Vander Heiden, M.G.; DeBerardinis, R.J. Understanding the Intersections between Metabolism and Cancer Biology. Cell 2017, 168, 657-669. [CrossRef]

14. Goodwin, C.M.; Xu, S.; Munger, J. Stealing the Keys to the Kitchen: Viral Manipulation of the Host Cell Metabolic Network. Trends Microbiol. 2015, 23, 789-798. [CrossRef]

15. Fleming, J.C.; Woo, J.; Moutasim, K.; Mellone, M.; Frampton, S.J.; Mead, A.; Ahmed, W.; Wood, O.; Robinson, H.; Ward, M.; et al. HPV, tumour metabolism and novel target identification in head and neck squamous cell carcinoma. Br. J. Cancer 2019, 120, 356-367. [CrossRef]

16. Montrose, D.C.; Galluzzi, L. Drugging cancer metabolism: Expectations vs. reality. Int. Rev. Cell Mol. Biol. 2019, 347, 1-26.

17. Enríquez, J.A. Supramolecular Organization of Respiratory Complexes. Annu. Rev. Physiol. 2016, 78, 533-561. [CrossRef]

18. Spruance, S.L.; Reid, J.E.; Grace, M.; Samore, M. Hazard ratio in clinical trials. Antimicrob. Agents Chemother. 2004, 48, 2787-2792. [CrossRef]

19. Goodman, M.T.; Saraiya, M.; Thompson, T.D.; Steinau, M.; Hernandez, B.Y.; Lynch, C.F.; Lyu, C.W.; Wilkinson, E.J.; Tucker, T.; Copeland, G.; et al. Human papillomavirus genotype and oropharynx cancer survival in the United States of America. Eur. J. Cancer 2015, 51, 2759-2767. [CrossRef]

20. O’Rorke, M.A.; Ellison, M.V.; Murray, L.J.; Moran, M.; James, J.; Anderson, L.A. Human papillomavirus related head and neck cancer survival: A systematic review and meta-analysis. Oral Oncol. 2012, 48, 1191-1201. [CrossRef]

21. Bratman, S.V.; Bruce, J.P.; O’Sullivan, B.; Pugh, T.J.; Xu, W.; Yip, K.W.; Liu, F.F. Human papillomavirus genotype association with survival in head and neck squamous cell carcinoma. JAMA Oncol. 2016, 2, 823-826. [CrossRef]

22. Chatfield-Reed, K.; Gui, S.; O'Neill, W.Q.; Teknos, T.N.; Pan, Q. HPV33+ HNSCC is associated with poor prognosis and has unique genomic and immunologic landscapes. Oral Oncol. 2020, 100, 104488. [CrossRef]

23. Gameiro, S.F.; Kolendowski, B.; Zhang, A.; Barrett, J.W.; Nichols, A.C.; Torchia, J.; Mymryk, J.S. Human papillomavirus dysregulates the cellular apparatus controlling the methylation status of H3K27 in different human cancers to consistently alter gene expression regardless of tissue of origin. Oncotarget 2017, 8 , 72564-72576. [CrossRef]

24. Cruz-Gregorio, A.; Aranda-Rivera, A.K.; Aparicio-Trejo, O.E.; Coronado-Martínez, I.; Pedraza-Chaverri, J.; Lizano, M. E6 oncoproteins from high-risk human papillomavirus induce mitochondrial metabolism in a head and neck squamous cell carcinoma model. Biomolecules 2019, 9, 351. [CrossRef]

25. Ma, D.; Huang, Y.; Song, S. Inhibiting the HPV16 oncogene-mediated glycolysis sensitizes human cervical carcinoma cells to 5-fluorouracil. Onco Targets Ther. 2019, 12, 6711-6720. [CrossRef] 
26. Guo, Y.; Meng, X.; Ma, J.; Zheng, Y.; Wang, Q.; Wang, Y.; Shang, H. Human papillomavirus 16 E6 contributes HIF- $1 \alpha$ induced warburg effect by attenuating the VHL-HIF- $1 \alpha$ interaction. Int. J. Mol. Sci. 2014, 15, 7974-7986. [CrossRef]

27. Neuzil, J.; Dyason, J.C.; Freeman, R.; Dong, L.F.; Prochazka, L.; Wang, X.F.; Scheffler, I.; Ralph, S.J. Mitocans as anti-cancer agents targeting mitochondria: Lessons from studies with vitamin e analogues, inhibitors of complex II. J. Bioenerg. Biomembr. 2007, 39, 65-72. [CrossRef]

28. Kanai, K.; Kikuchi, E.; Mikami, S.; Suzuki, E.; Uchida, Y.; Kodaira, K.; Miyajima, A.; Ohigashi, T.; Nakashima, J.; Oya, M. Vitamin E succinate induced apoptosis and enhanced chemosensitivity to paclitaxel in human bladder cancer cells in vitro and in vivo. Cancer Sci. 2010, 101, 216-223. [CrossRef]

29. Gu, X.; Song, X.; Dong, Y.; Cai, H.; Walters, E.; Zhang, R.; Pang, X.; Xie, T.; Guo, Y.; Sridhar, R.; et al. Vitamin E Succinate Induces Ceramide-Mediated Apoptosis in Head and Neck Squamous Cell Carcinoma In vitro and In vivo. Clin. Cancer Res. 2008, 14, 1840-1848. [CrossRef]

30. Oliva, C.R.; Markert, T.; Ross, L.J.; White, E.L.; Rasmussen, L.; Zhang, W.; Everts, M.; Moellering, D.R.; Bailey, S.M.; Suto, M.J.; et al. Identification of small molecule inhibitors of human cytochrome coxidase that target chemoresistant glioma cells. J. Biol. Chem. 2016, 291, 24188-24199. [CrossRef]

31. Kim, K.K.; Abelman, S.; Yano, N.; Ribeiro, J.R.; Singh, R.K.; Tipping, M.; Moore, R.G. Tetrathiomolybdate inhibits mitochondrial complex IV and mediates degradation of hypoxia-inducible factor- $1 \alpha$ in cancer cells. Sci. Rep. 2015, 5, 14296. [CrossRef] [PubMed]

32. Siebring-van Olst, E.; Blijlevens, M.; de Menezes, R.X.; van der Meulen-Muileman, I.H.; Smit, E.F.; van Beusechem, V.W. A genome-wide siRNA screen for regulators of tumor suppressor p53 activity in human non-small cell lung cancer cells identifies components of the RNA splicing machinery as targets for anticancer treatment. Mol. Oncol. 2017, 11, 534-551. [CrossRef]

33. Butz, K.; Whitaker, N.; Denk, C.; Ullmann, A.; Geisen, C.; Hoppe-Seyler, F. Induction of the p53-target gene GADD45 in HPV-positive cancer cells. Oncogene 1999, 18, 2381-2386. [CrossRef] [PubMed]

34. Dabir, D.V.; Hasson, S.A.; Setoguchi, K.; Johnson, M.E.; Wongkongkathep, P.; Douglas, C.J.; Zimmerman, J.; Damoiseaux, R.; Teitell, M.A.; Koehler, C.M. A Small Molecule Inhibitor of Redox-Regulated Protein Translocation into Mitochondria. Dev. Cell 2013, 25, 81-92. [CrossRef]

35. The Cancer Genome Atlas Network Comprehensive genomic characterization of head and neck squamous cell carcinomas. Nature 2015, 517, 576-582. [CrossRef]

36. Shimamura, K.; Kitazawa, H.; Miyamoto, Y.; Kanesaka, M.; Nagumo, A.; Yoshimoto, R.; Aragane, K.; Morita, N.; Ohe, T.; Takahashi, T.; et al. 5,5-Dimethyl-3-(5-methyl-3-oxo-2-phenyl-2,3-dihydro-1H-pyrazol-4-yl)-1-phenyl-3-(trifluoromethyl)-3,5,6,7tetrahydro-1H-indole-2,4-dione, a Potent Inhibitor for Mammalian Elongase of Long-Chain Fatty Acids Family 6. J. Pharmacol. Exp. Ther. 2009, 330, 249-256. [CrossRef]

37. Shimamura, K.; Nagumo, A.; Miyamoto, Y.; Kitazawa, H.; Kanesaka, M.; Yoshimoto, R.; Aragane, K.; Morita, N.; Ohe, T.; Takahashi, T.; et al. Discovery and characterization of a novel potent, selective and orally active inhibitor for mammalian ELOVL6. Eur. J. Pharmacol. 2010, 630, 34-41. [CrossRef]

38. Granchi, C. ATP citrate lyase (ACLY) inhibitors: An anti-cancer strategy at the crossroads of glucose and lipid metabolism. Eur. J. Med. Chem. 2018, 157, 1276-1291. [CrossRef]

39. Migita, T.; Okabe, S.; Ikeda, K.; Igarashi, S.; Sugawara, S.; Tomida, A.; Soga, T.; Taguchi, R.; Seimiya, H. Inhibition of ATP citrate lyase induces triglyceride accumulation with altered fatty acid composition in cancer cells. Int. J. Cancer 2014, 135, 37-47. [CrossRef]

40. Hong, R.; Zhang, W.; Xia, X.; Zhang, K.; Wang, Y.; Wu, M.; Fan, J.; Li, J.; Xia, W.; Xu, F.; et al. Preventing BRCA1/ZBRK1 repressor complex binding to the GOT2 promoter results in accelerated aspartate biosynthesis and promotion of cell proliferation. Mol. Oncol. 2019, 13, 959-977. [CrossRef]

41. Weitzel, J.M.; Alexander Iwen, K. Coordination of mitochondrial biogenesis by thyroid hormone. Mol. Cell. Endocrinol. 2011, 342, 1-7. [CrossRef]

42. Braun, D.; Kim, T.D.; Le Coutre, P.; Köhrle, J.; Hershman, J.M.; Schweizer, U. Tyrosine kinase inhibitors noncompetitively inhibit MCT8-mediated iodothyronine transport. J. Clin. Endocrinol. Metab. 2012, 97, 100-105. [CrossRef]

43. Schmitz, S.; Ang, K.K.; Vermorken, J.; Haddad, R.; Suarez, C.; Wolf, G.T.; Hamoir, M.; Machiels, J.-P. Targeted therapies for squamous cell carcinoma of the head and neck: Current knowledge and future directions. Cancer Treat. Rev. 2014, 40, 390-404. [CrossRef] 
44. Ghasemi, F.; Black, M.; Sun, R.X.; Vizeacoumar, F.; Pinto, N.; Ruicci, K.M.; Yoo, J.; Fung, K.; MacNeil, D.; Palma, D.A.; et al. High-throughput testing in head and neck squamous cell carcinoma identifies agents with preferential activity in human papillomavirus-positive or negative cell lines. Oncotarget 2018, 9, 26064-26071. [CrossRef]

45. Johannes, J.; Jayarama-Naidu, R.; Meyer, F.; Wirth, E.K.; Schweizer, U.; Schomburg, L.; Köhrle, J.; Renko, K. Silychristin, a flavonolignan derived from the milk thistle, is a potent inhibitor of the thyroid hormone transporter MCT8. Endocrinology 2016, 157, 1694-1701. [CrossRef]

46. Hercbergs, A.; Johnson, R.E.; Ashur-Fabian, O.; Garfield, D.H.; Davis, P.J. Medically Induced Euthyroid Hypothyroxinemia May Extend Survival in Compassionate Need Cancer Patients: An Observational Study. Oncologist 2015, 20, 72-76. [CrossRef]

47. Hercbergs, A.; Mousa, S.A.; Leinung, M.; Lin, H.Y.; Davis, P.J. Thyroid Hormone in the Clinic and Breast Cancer. Horm. Cancer 2018, 9, 139-143. [CrossRef]

48. Cayrol, F.; Sterle, H.A.; Díaz Flaqué, M.C.; Barreiro Arcos, M.L.; Cremaschi, G.A. Non-genomic Actions of Thyroid Hormones Regulate the Growth and Angiogenesis of T Cell Lymphomas. Front. Endocrinol. (Lausanne) 2019, 10, 63. [CrossRef]

49. Fortelny, N.; Overall, C.M.; Pavlidis, P.; Cohen Freue, G.V. Can we predict protein from mRNA levels? Nature 2017, 547, E19-E23. [CrossRef]

50. Leek, J.T.; Scharpf, R.B.; Bravo, H.C.; Simcha, D.; Langmead, B.; Johnson, W.E.; Geman, D.; Baggerly, K.; Irizarry, R.A. Tackling the widespread and critical impact of batch effects in high-throughput data. Nat. Rev. Genet. 2010, 11, 733-739. [CrossRef]

51. Hwang, B.; Lee, J.H.; Bang, D. Single-cell RNA sequencing technologies and bioinformatics pipelines. Exp. Mol. Med. 2018, 50, 96. [CrossRef] [PubMed]

52. Aran, D.; Sirota, M.; Butte, A.J. Systematic pan-cancer analysis of tumour purity. Nat. Commun. 2015, 6, 8971. [CrossRef] [PubMed]

53. Kaelin, W.G. Common pitfalls in preclinical cancer target validation. Nat. Rev. Cancer 2017, 17, 441-450. [CrossRef]

54. The Cancer Genome Atlas Research Network; Chang, K.; Creighton, C.J.; Davis, C.; Donehower, L.; Drummond, J.; Wheeler, D.; Ally, A.; Balasundaram, M.; Birol, I.; et al. The Cancer Genome Atlas Pan-Cancer analysis project. Nat. Genet. 2013, 45, 1113-1120. [CrossRef]

55. Bolaños, J.P.; Almeida, A.; Moncada, S. Glycolysis: A bioenergetic or a survival pathway? Trends Biochem. Sci. 2010, 35, 145-149. [CrossRef]

56. Chen, J.Q.; Russo, J. Dysregulation of glucose transport, glycolysis, TCA cycle and glutaminolysis by oncogenes and tumor suppressors in cancer cells. Biochim. Biophys. Acta Rev. Cancer 2012, 1826, 370-384. [CrossRef]

57. Sharma, L.K.; Lu, J.; Bai, Y. Mitochondrial respiratory complex I: Structure, function and implication in human diseases. Curr. Med. Chem. 2009, 16, 1266-1277. [CrossRef]

58. Kluckova, K.; Bezawork-Geleta, A.; Rohlena, J.; Dong, L.; Neuzil, J. Mitochondrial complex II, a novel target for anti-cancer agents. Biochim. Biophys. Acta Bioenerg. 2013, 1827, 552-564. [CrossRef]

59. Owens, K.M.; Kulawiec, M.; Desouki, M.M.; Vanniarajan, A.; Singh, K.K. Impaired OXPHOS complex III in breast cancer. PLoS ONE 2011, 6, e23846. [CrossRef]

60. Guo, R.; Gu, J.; Wu, M.; Yang, M. Amazing structure of respirasome: Unveiling the secrets of cell respiration. Protein Cell 2016, 7, 854-865. [CrossRef]

61. Mansilla, N.; Racca, S.; Gras, D.E.; Gonzalez, D.H.; Welchen, E. The complexity of mitochondrial complex iv: An update of cytochrome c oxidase biogenesis in plants. Int. J. Mol. Sci. 2018, 19, 662. [CrossRef] [PubMed]

62. Jonckheere, A.I.; Smeitink, J.A.M.; Rodenburg, R.J.T. Mitochondrial ATP synthase: Architecture, function and pathology. J. Inherit. Metab. Dis. 2012, 35, 211-225. [CrossRef] [PubMed]

63. Kuo, C.Y.; Ann, D.K. When fats commit crimes: Fatty acid metabolism, cancer stemness and therapeutic resistance. Cancer Commun. 2018, 38, 47. [CrossRef] [PubMed]

64. Currie, E.; Schulze, A.; Zechner, R.; Walther, T.C.; Farese, R.V. Cellular fatty acid metabolism and cancer. Cell Metab. 2013, 18, 153-161. [CrossRef]

65. Koundouros, N.; Poulogiannis, G. Reprogramming of fatty acid metabolism in cancer. Br. J. Cancer 2019, 122, 4-22. [CrossRef] 
66. Guillou, H.; Zadravec, D.; Martin, P.G.P.; Jacobsson, A. The key roles of elongases and desaturases in mammalian fatty acid metabolism: Insights from transgenic mice. Prog. Lipid Res. 2010, 49, $186-199$. [CrossRef]

67. Houten, S.M.; Wanders, R.J.A. A general introduction to the biochemistry of mitochondrial fatty acid ß-oxidation. J. Inherit. Metab. Dis. 2010, 33, 469-477. [CrossRef]

68. Jin, L.; Alesi, G.N.; Kang, S. Glutaminolysis as a target for cancer therapy. Oncogene 2016, 35, 3619-3625. [CrossRef]

69. Patra, K.C.; Hay, N. The pentose phosphate pathway and cancer. Trends Biochem. Sci. 2014, 39, 347-354. [CrossRef]

70. Ashburner, M.; Ball, C.A.; Blake, J.A.; Botstein, D.; Butler, H.; Cherry, J.M.; Davis, A.P.; Dolinski, K.; Dwight, S.S.; Eppig, J.T.; et al. Gene Ontology: Tool for the unification of biology. Nat. Genet. 2000, 25, 25-29. [CrossRef]

71. The Gene Ontology Consortium The Gene Ontology Resource: 20 years and still GOing strong. Nucleic Acids Res. 2018, 47, D330-D338.

72. Mi, H.; Muruganujan, A.; Ebert, D.; Huang, X.; Thomas, P.D. PANTHER version 14: More genomes, a new PANTHER GO-slim and improvements in enrichment analysis tools. Nucleic Acids Res. 2019, 47, D419-D426. [CrossRef] [PubMed]

73. Pavlova, N.N.; Thompson, C.B. The Emerging Hallmarks of Cancer Metabolism. Cell Metab. 2016, 23, $27-47$. [CrossRef] [PubMed]

(C) 2020 by the authors. Licensee MDPI, Basel, Switzerland. This article is an open access article distributed under the terms and conditions of the Creative Commons Attribution (CC BY) license (http://creativecommons.org/licenses/by/4.0/). 